\title{
COURIER SERVICES IN INDIA: CONCERNS FOR EFFECTIVE SERVICE DELIVERY
}

\author{
Sandhya Anvekar*
}

\section{ABSTRACT:}

The courier industry in India is like a vital link of communication between persons and corporations meant for individual and industrial benefits. It is an industry worth Rs. 50 billions and is on steady pace of development. More than 2300 courier companies operating in India, it is a challenge for the service provider of courier services to be unique, competent and provide effective service delivery.

An insight into the crucial and critical incidents of service failure and strategizing by closing these failures will ensure effective service deliveries by the courier service providers. A trained and skilled front stage personnel, committed delivery boys/runners and efficient distribution networking can enable the courier service operators to provide failure free effective senvice delivery.

\section{Introduction:}

A courier is a person or a company employed to deliver messages, packages and mail.(1). Courier services are different from ordinary mail services because of their

* Faculty of Mount Carmel Instifute of Management, Bangalore - 560 052, Karnataka. 
personalised and customized nature, speed, secrecy, easy tracking and assured service delivery commitments. Due to these service features, the couriers are usually more expensive than usual mail services. The courier services have a systematized net work in the typical hub and spoke model and their mechanism is carried out by all hub center in-charges with a well planned, co-coordinated transport system of vans, bus, trains and air couriers inter connecting all destinations. All the latest electronic information systems like pagers, trunk radios, cellular phones etc., are being used to yield greater operational efficiency and high productivity.

The courier services are spread inside a country like a lifeline in different regions operating from all cities to regional, national and global destinations. The world's largest courier companies are UPS, followed by FedEx of USA and DHL, a German company. The courier service industry in India is of recent origin. (2) The Indian Postal Service which serves the public from 155,000 post offices and is believed to have the most widely distributed system in the world (China has 57,000, Russia 41,000 and the United States 38,000 offices)(3) was the most significant service operator in the courier business.

The increased demand for services, efficiency and professonalism gave impetus to developement of courier business in India. Though the Indian postal service provided many value added facilities like- general or registered mail, parcel post, speed post, greeting post, express post, media post, e post and special courier service known as EMS-speed post it failed to cater to mounting demand, general inefficiency of services and customer dissatisfaction of general public and the private business.

The courier business in India witnessed DHL entering in business in 1979 later paving way for First Flight, Overnite, Blaze Flash, TNT and World Wide Express and so on. Today the courier industry, being one of the fastest growing industries, is of more than Rs.50 billion in revenues (in 2004-2005). When compared to US economy which has, according to the Datamonitor, the overall US express and parcels delivery market worth $\$ 65$ billion, Indian courier industry is much behind. (4) With 2300 courier companies i.e. Indian courier and express industry comprises companies operating in domestic as well as international markets and companies having wide reach within the limited geographic area and local intra-city market. There are nearly 20 in the organised sector, 2000 in semi organized sector and remaining in unorganized sector. (5) It employs around 1,00,000 people and plays a vital service role for trade and industry in 
general, by providing time-definite, door-to-door delivery of letters, parcels and commercial consignments, which is a critical need of modern businesses.

In India, DHL, Blue Dart, Elbee, Sky Pak and AFL are the major service operators. Blue Dart being the market leader owns three Boeing $737 \mathrm{~s}$ and carries large volumes of packages and makes overnight deliveries. It made Rs. 41 crores profits in 2003. 04 by offering logistics and e-commerce solutions for corporate customers. Both Blue Dart and Elbee serve more than 1200 destinations in the country and have international tie-ups.(6)

\section{Courier Services - An Industrial Profile}

The profile of courier service industry can be highlighted by its following unique features-

- Modes of services- Before the industrialization, in most of the countries, runners and homing pigeons were used to deliver timely messages. When the horse became domesticated its use was rapidly adopted by couriers. Before there were mechanized courier services foot messengers physically ran miles to their destinations. To this day there are marathons directly related to actual historical messenger routes. (7) Now in the modern era, the railways, automobiles and airplanes are the most commonly employed for service delivery.

- Nature of service operators- The courier services industry is mostly lies with the private operators in India and the governement run package transportation service providers do not compete toughly with them. Besides this is one industry which is not heavily regulated by the government.

- Lesser regulations- There are no entry and exit barriers by the government and exit is mostly prompted by a better price bargain. Besides the tax regulations are minimal in nature that apply to courier services industry.

- Intra sectoriral interdependence- The growth of courier industry is highly dependent on the growth of commerce and trade, economic development, and foreign trade. It acts as an ancillary server and supports these sectors as a mutual business partner. 
- Unique Selling Proposition(USP)- A courier service makes a difference only on account of speedy service, efficiency, and proper delivery to destined customer and destination. The costing of courier services though little higher than the state owned operators, the customer trust and satisfaction on reliable services is the USP of the courier services offered by a corporate service provider.

- High manpower intensity- Indian courier industry is highly labour intensive which requires a band of service personnel who are prompt, efficient and reliable to service commitment. The use of mechanised devices in services is limited only for record maintenance, tracking of packages and parcels, office management and transit destinations. The skilled manpower is the main backbone of the efficient service delivery.

- Investment pattern- The service provider in courier industry has to invest lessser on the service scape and the physical evidence but has to spend more on the distribution networking, technology and manpower training. A regular check on the service delivery and distribution networking requires most of the communicational costs.

- Customer profile- The customer of courier services is any person from the society either taking up personal, professional or business form of service purpose. Besides the component of service delivery can be either a commodity parcel or a baggage or a written document to be reached to a specific destination.

- Franchising- The courier industry has a wide use of business franchising wherein the courier company franchises its operations under same brand and company name so as to reach destinations in the distribution networking channels.

\section{Service Organisation of a Courier Company}

The service organisation for any courier sevice provider is a typical structure wherein the office management is lesser and distribution networking is more in operations. The service organisation of a courier operator is viewed in the following manner (8)- 


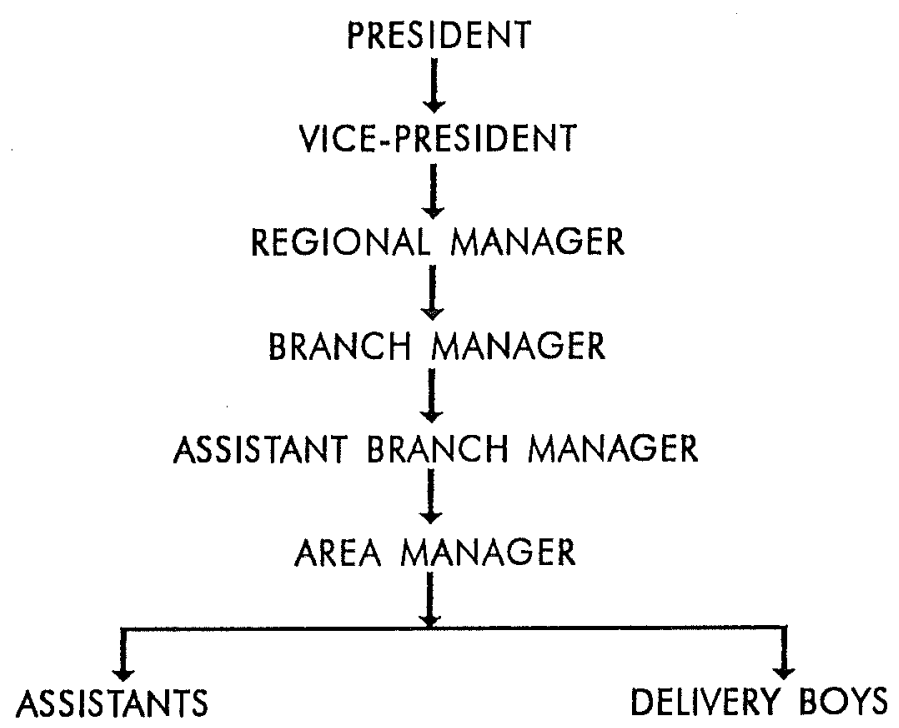

The service organisation of a courier service provider is a simple structure that depicts the service process and the critical incidents in the service delivery in a simplified manner.

\section{Courier Service Delivery Process}

The following flow chart explains how a courier service is being operated by a provider in a typical process in the service providers premises. In few instances the running boys visit the customer premises and collect the consignments depending on the credibility and frequency of service transanctions with the business customers(8)

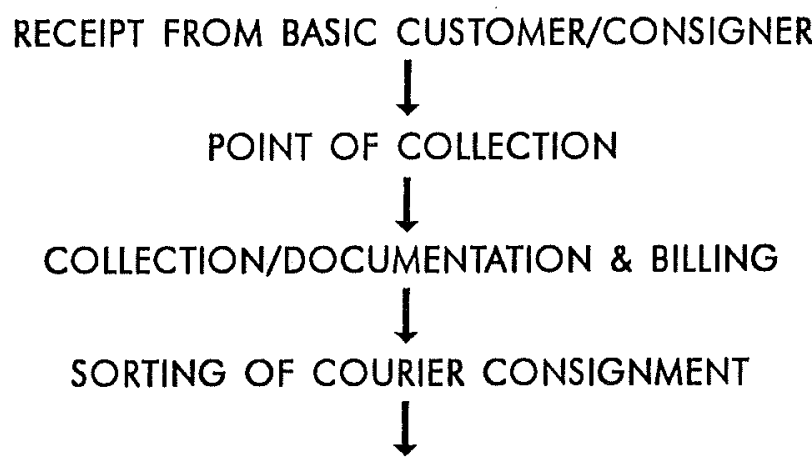




\section{DELIVERY FROM REGIONAL OFFICES TO OERATIONS OFFICE $\downarrow$ BAR CODING THE CONSIGNMENT<smiles>[CH]C</smiles> TRANSIT $\downarrow$ \\ DUMPING IN THE LOCAL DESTINATION BRANCH OFFICES $\downarrow$ \\ DELIVERY TO FINAL CUSTOMER/CONSIGNEE}

\section{Critical Incidents of Service Failure}

The type of service delivery divides the services into two types - same day delivery and overnight delivery. To compete and survive in the courier industry, service providers need to be professional, customer oriented, and capable of delivering shipments to various destinations safely and quickly. (9) To ensure speedy delivery and quality services, the service provider of courier industry has to basically identify the points of critical incidents of service failure and focus on closing these points to provide quality in services and customer satisfaction. The possible service failures in the courier service process are-

- Inaccurate and incomplete documentation of consignee addressThe front office assistant documenting the inputs for billing must record the consignee's address and locational landmarks accurately lest it results in non delivery of the consignment.

- Availability of the consignee on recorded location- The courier service front office staff must ensure the availbility of the consignee on the recorded location from the consigner otherwise delivery is not ensured.

- Consignment delivery to authentic receiver- The delivery personnel or the running boys should deliver the consignment to the addressee or an authentic representative of the consignee failing which it reaches to irrelevant hands.

- Faulty bar coding- The sorting and faulty bar coding of pin numbers and type of consignment leads to faulty delivery and more gestation for delivery of 
courier service. In India, there are many towns and villages bearing similar names in different states leading to confusion.

- Incourteous interaction with front stage personnel- The front stage personnel like office assistants, branch manager and the customer care officer play a signifcant role in customer satisfaction and retention. Assured delivery, comitted and prompt services and proper response to customers should be the USP of a courier industry.

- Safety of the baggage/parcels- There are many possibilities of loss or damange to consignments especially if they are fragile items, liquids or chemical substances like medicines. The courier service provider must ensure the safety of the consignement by protective wrapping or packaging, careful handling on transit and in tact delivery of the items.

- Easy tracking and tracing of consignments- The office management must ensure an advanced computerized system of easily tracking and tracing of consignments on transit as and when necessiated.

- Cost effective pricing- Most of the courier companies follow the flat price slab strategy and it sounds little higher when compared with different companies. To give quality services and customer satisfaction, differential pricing can be adopted and customer loyalty discounts can be provided for further customer refention.

- Recovery of lost baggage/parcels- This is one particular area of concern where the courier services provider bears the least responsibility and has a greater impact on customer satisfaction and quality services. Most of the operators legally bear almost neglibile responsibility when a parcel or a baggage is lost. Effective service delivery must ensure the assured tracing or bearing maximum burden of compensation of the lost parcel/baggage or else must ensure the safe recovery of it.

\section{Conclusion:}

In India, the courier service industry is one of the growing business activities. Being a Rs. 50 billion industry and highly manpower intensive services, it has a great potential in our country. The courier companies either in state or private sectors have to face the challenges of quality services, customer satisfaction and retention, effective service delivery with reasonable pricing if they have to compete and survive in the business. A focus on service delivery critical incidents and strategy to warrant these incidents will fasten the speed of these companies and achieve quality services. 


\section{References:}

1. Fincham, Ben (2004-01), Bicycle Couriers in the 'New' Economy, Cardiff University, page 5.

2. S.M.Jha, 'Services Marketing', Himalaya Publishing House, 2006, pp.635.

3. Airline baggage rate hike will cripple courier services: $\mathrm{EICl}$ Our Corporate Bureau, 18 June 2003.

4. China to become world's sixth largest Express market by 2010 Our Corporate Bureau, 18 May 2006.

5. Services Markefing, ICFAl Centre for Management Research, Hyderabad, pp.427.

6. ibid.

7. Fincham, Ben (2004-01), Bicycle Couriers in the 'New' Economy, Cardiff University, page 5 .

8. Personal visits to DTDC, Professional Couriers, VRL Cargo, Bangalore.

9. ICFAl, ibid.

10. www.google.com. 